\title{
A gestão pública municipal no desenvolvimento do turismo nas áreas naturais protegidas de Joinville (SC)
}

\section{The municipal public administration in the development of tourism in protected natural areas in Joinville (SC, Brazil)}

\author{
Vinicius Boneli Vieira, José Manoel Gonçalves Gândara
}

\section{RESUMO}

O presente artigo tem por objetivo analisar a gestão pública municipal para o desenvolvimento do turismo nas áreas naturais protegidas de Joinville, localizado na região norte do Estado de Santa Catarina. Para a caracterização das áreas naturais protegidas, utilizou-se como métodos o estudo exploratório, que permitiu a realização de uma análise documental, bem como a realização da observação participante na gestão pública municipal do meio ambiente e do turismo, e diretamente nas áreas naturais protegidas e suas comunidades. Também foi realizada a coleta de dados através de questionário quanti-qualitativo aplicado aos 42 conselheiros do Conselho Municipal do Meio Ambiente e do Conselho Municipal de Turismo. O diagnóstico realizado a partir dos elementos que constituem a caracterização de cada área e da coleta de dados permitiu reunir, através da análise DAFO, os pontos críticos, justificados pelas debilidades e ameaças, assim como, ações possíveis conforme as fortalezas e oportunidades. Perceberam-se inúmeras debilidades e ameaças geradas pelo incipiente processo de gestão e falta de participação e mobilização das comunidades locais para uma gestão participativa, as quais têm comprometido os objetivos fundamentais de conservação e preservação. No entanto, as ferramentas de planejamento e gestão, assim como as características de relevantes fragmentos naturais e socioculturais identificadas como fortalezas, convergem para as oportunidades as quais remetem a possibilidade de ações focadas para o planejamento participativo e 0 desenvolvimento do turismo nas áreas naturais protegidas.

PALAVRAS-CHAVE: Turismo; Gestão Pública; Áreas Naturais Protegidas; Desenvolvimento do Turismo; Joinville (SC). 


\begin{abstract}
This study aims to analyze the municipal public administration for development of tourism in protected natural areas of Joinville, located in the northern state of Santa Catarina, Brazil. For the characterization of protected natural areas, was used as methods exploratory study, which allowed for an analysis of documents, as well as conducting participant observation in municipal public management of the environment and tourism, and directly into the areas natural protected and their communities. Was also performed to collect data through quantitative and qualitative questionnaire applied to 42 councilors of the Municipal Council on the Environment and the Municipal Tourism Council. The diagnosis from the elements that constitute the characterization of each area and data collection brought together through the SWOT analysis, critical points, justified by the weaknesses and threats, as well as possible actions according to the strengths and opportunities. They saw themselves numerous weaknesses and threats generated by the incipient process of management and lack of participation and mobilization of local communities for participatory management, which have compromised the fundamental goals of conservation and preservation. However, the tools of planning and management, as well as the characteristics of fragments relevant natural and socio-cultural identified as strengths, converge to the opportunities which relate the possibility of actions focused to participatory planning and development of tourism in protected natural areas.

KEYWORDS: Tourism; Public Management; Protected Natural Areas; Tourism Development; Joinville (SC, Brazil).
\end{abstract}

\title{
Introdução
}

O processo de crescimento do fenômeno turístico, suas tendências desde 1999, principalmente na massificação da atividade em destinos turísticos, assim como ações voltadas ao desenvolvimento local e regional, tem despertado na Geografia um interesse maior pelo seu estudo de forma científica. As incidências espaciais do turismo têm recebido em destaque um tratamento geográfico do fenômeno (RODRIGUES, 1999).

O estudo das dimensões espaciais do turismo tem refletido inúmeras análises por meio de estudiosos da geografia (CORIOLANO, 2007, 2009; CARLOS, 1996; CRUZ, 2007; RODRIGUES, 1996, 1999; XAVIER, 2007) que identificam a dinamicidade e complexidade do fenômeno turístico enquanto agente de transformação e organização do território. Para compreensão do espaço e do território, utilizam-se também nesta pesquisa, conceitos de geógrafos como: Lefebvre (1999; 2000), Castro (2003), Claval (1999) e Haesbaert (1999; 2007).

A relação entre sociedade-natureza e turismo é descrita por Coriolano (2007) através da apropriação da natureza pelo homem, transformando-a em espaço geográfico a partir da sua presença e de suas interferências. Segundo a autora, este processo, dado em um espaço, define o surgimento de cidades, lugares, paisagens, territórios e ambientes para a realização do turismo. 
A sociedade determina as formas de uso (consumo) da natureza ou mais precisamente do espaço, do trabalho e da riqueza. Diante deste consumo ocorre a espacialidade para e pelo turismo, juntamente com outras atividades de apoio como: transportes, hospedagem, agenciamento, alimentação, entretenimento, compras, além de outras ações mercadológicas.

As condições espaciais da atividade turística e da apropriação territorial dos lugares "turistificados", ou pseudo-lugares, sem historicidade, carregadas de artificialidades e a serviço do turismo ou do lazer, também são abordados por Cruz (2007), com base nos recursos teóricos e metodológicos da geografia para estudos das implicações da atividade socioeconômica.

Estudos da geografia do turismo também relatam o desenvolvimento do fenômeno do turismo não somente pela ótica econômica, mas abordado no âmbito multi e transdisciplinar, integrando os aspectos históricos, psicológicos, sociológicos, antropológicos, políticos, culturais, ecológicos, dentre outros (RODRIGUES, 1996; 1999).

Este processo da discussão do turismo na geografia aponta resultados significativos no desenvolvimento do fenômeno, principalmente no planejamento da atividade, levantando principalmente os impactos do turismo nas comunidades locais e os custos sociais das obras e da manutenção dos serviços públicos nos núcleos turísticos receptores.

O processo de gestão das cidades encontra-se repleto de desafios, pois há necessidade de contemplar diferentes necessidades em relação aos aspectos fundamentais para a vida humana, buscando proporcionar a qualidade de vida. Dentre os temas presentes neste processo de gestão estão as questões ambientais, o lazer e o turismo. Gerir responsavelmente os espaços de convivência do homem é tarefa primordial para o difícil alcance da sustentabilidade. Neste contexto, propõe-se a discussão da gestão pública das áreas naturais protegidas (ANP) no município de Joinville, localizado na região sul do Brasil, no Estado de Santa Catarina.

Diante do processo de análise, se estabeleceu como problema de pesquisa o seguinte questionamento: A gestão pública municipal das áreas naturais protegidas de Joinville esta sendo efetiva e aproveitando o potencial destas para seu uso para o turismo?

A reflexão sobre estas áreas visa explicitar a concepção de gestão quanto à conservação dos ambientes naturais protegidos e sua interação com o planejamento e desenvolvimento do turismo. Assim, o objetivo desta pesquisa foi de analisar a gestão pública municipal para o desenvolvimento do turismo nas áreas naturais protegidas de Joinville e os objetivos específicos foram de caracterização das áreas naturais protegidas, avaliação da gestão pública municipal do meio ambiente e do turismo, considerando as opiniões dos conselheiros do Conselho Municipal do Meio Ambiente de Joinville (COMDEMA) e Conselho Municipal de Turismo de Joinville (COMTUR) e análise do potencial e das limitações das áreas naturais protegidas para o desenvolvimento do turismo em áreas naturais em Joinville. 


\section{Procedimentos metodológicos}

O presente estudo, baseado na historicidade, somado a reflexões teóricas, dos campos da geografia e turismo, discorre sobre a temática da natureza, mais especificamente das áreas naturais protegidas.

Basicamente, a metodologia aplicada na pesquisa corresponde à caracterização das áreas naturais protegidas, que envolve o processo de análise documental, a observação participante, a pesquisa através de questionário quanti-qualitativo aplicado aos conselheiros do Conselho Municipal de Meio Ambiente e do Conselho Municipal de Turismo; e a análise através do diagnóstico turístico e do método DAFO que se utiliza da caracterização e das relações externas para indicação os pontos fortes e fracos, oportunidades e ameaças para o desenvolvimento do turismo'.

Barretto (2005) compreende o diagnóstico como a investigação, a reflexão, a compreensão e o juízo dos dados provenientes de realidade empírica (com base no inventário turístico), com fins de operacionalização. A pesquisa para o diagnóstico deve objetivar ações para o futuro. Caracterizase como uma etapa demorada, um estudo exploratório com necessidade de se traçar um marco com situações antecedentes em matéria de turismo no local estudado. A autora destaca que devem ser definidas áreas críticas de necessidade para a intervenção futura se tornar imperativa, assim como, no diagnóstico deve-se buscar elementos para justificar as ações, com apoio das teorias dentro de um marco ético. A análise da situação atual do destino turístico requer um profundo trabalho de reflexão, uma visão objetiva e abrangente que estará impregnada de valores dos pesquisadores e de sua bagagem teórica.

Segunda a Organização Mundial do Turismo (2003), na formulação de diagnósticos para o turismo grande parte dos autores cita como instrumento a análise SWOT. Constitui em uma técnica para resumir as grandes oportunidades e os maiores limites de desenvolvimento turístico. SWOT refere-se à identificação em inglês de pontos fortes (strengths), pontos fracos (weaknesses), oportunidades (opportunities) e ameaças (threats). No Brasil, é traduzida, certas vezes como em espanhol por DAFO (deficiências, ameaças, fortalezas e oportunidades).

Quanto ao SWOT, Valls (2006) destaca as competências da organização (destino) - conhecimento, tecnologias, objetivos econômicos e sociais, vantagens competitivas, dentre outros; os atores-chave, valores do destino e a carteira de produtos potenciais e comercializados. $\mathrm{O}$ autor complementa a ideia de análise SWOT ressaltando a mesma como a análise competitiva que vem eleger o posicionamento estratégico do destino turístico em relação: aos produtos e mercados, as capacidades próprias do destino, as barreiras de entrada e saída do setor, a evolução da demanda, aos destinos substitutivos ou complementares, aos mercados-alvo e os segmentos, dentre outros tópicos necessários para a formulação de planos estratégicos de desenvolvimento turístico.

Esta pesquisa utiliza-se também da estratégia qualitativa de estudo multicasos envolvendo as áreas naturais protegidas de Joinville, conforme cadastro municipal de unidades de conservação da FUNDEMA. Foram caracterizadas 8 áreas naturais protegidas (Quadro 1), seguindo alguns 
critérios como de localização, visitação, caracterização e infraestrutura. Para a análise da gestão, teve-se como objetivo, abranger todas as ANP inseridas no território, considerando a relevância turística para o município.

Quadro 1: Áreas Naturais Protegidas de Joinville.

Table 1: Protected Natural Areas of Joinville

\begin{tabular}{|c|c|}
\hline Áreas naturais protegidas & área em $\mathrm{m}^{2}$ \\
\hline 1. Parque Municipal Morro do Finder & 500.000 \\
\hline 2. Parque Natural Municipal da Caieira & $1.279 .450,50$ \\
\hline $\begin{array}{l}\text { 3. Área de Relevante Interesse Ecológico do } \\
\text { Morro da Boa Vista e Parque Zoo-Botânico do } \\
\text { Morro da Boa Vista* }\end{array}$ & 3.960 .000 \\
\hline $\begin{array}{l}\text { 7. Área de Proteção Ambiental Serra Dona } \\
\text { Francisca }\end{array}$ & 408.420 .000 \\
\hline $\begin{array}{l}\text { 4. Reserva de Desenvolvimento Sustentável } \\
\text { da llha do Morro do Amaral }\end{array}$ & 34.000 \\
\hline 5. Estação Ecológica do Bracinho & 46.100 \\
\hline 6. Parque Rolf Colin & 18.503 .800 \\
\hline $\begin{array}{l}\text { 8. Reserva Particular de Patrimônio Natural } \\
\text { Caetezal }\end{array}$ & 46.130 .000 \\
\hline Total em área & $475.309 .350,50$ \\
\hline Total geral aproximada (em ha.) & 41.419** \\
\hline
\end{tabular}

Fonte: Autores. Source: Authors.

* Sendo 100.000 do Parque Zoo-Botânico.

** Não considerando no total as áreas da Estação Ecológica do Bracinho (com parte da sua área permanecendo no município de Schroeder), do Parque Rolf Colin e da RPPN Caetezal, sendo que estas estão inseridas na área APA Serra Dona Francisca.

Ainda como etapa do estudo multicaso, teve-se a concentração informações, bem como a aplicabilidade, através de entrevistas, baseado em um roteiro de questionamentos com especialistas conselheiros do Conselho Municipal do Meio Ambiente e Conselho Municipal do Turismo, dentre os quais podemos destacar os técnicos representantes dos órgãos públicos gestores (Fundação Municipal do Meio Ambiente de Joinville), técnicos representantes dos órgãos públicos diretamente relacionados ao turismo (Fundação de Promoção e Planejamento Turístico de Joinville); professores universitários vinculados a pesquisa e o planejamento das áreas naturais e das relações entre turismo território e meio ambiente; membros de instituições e organismos públicos e privados relacionados com 0 planejamento e gestão de turismo em espaços naturais e profissionais das áreas de consultoria com experiência em planejamento e gestão de turismo e espaços naturais.

Para a inserção dos participantes na pesquisa considerou-se a estreita vinculação entre a atividade profissional/institucional ou de pesquisa e o tema objeto de estudo. Acredita-se que o estudo multicaso aplicado não somente aos órgãos gestores, mas também entre os órgãos envolvidos com o turismo e o meio ambiente, poderá gerar subsídios capazes de fomentar 
uma análise detalhada e focada também na intersetorialidade da gestão das áreas naturais protegidas e seu reflexo no turismo.

Conforme Yin (2005), o estudo de caso é entendido como uma investigação empírica que busca analisar o contexto real de um fenômeno contemporâneo quando as definições entre o fenômeno e o contexto não estão bem definidas. Neste caso, o pesquisador assume uma posição de observador, sem nenhum controle sobre os eventos comportamentais, buscando resgatar características específicas na coleta e análise dos dados.

Diante sua finalidade, a pesquisa estabelece um caráter exploratório, descritivo, utilizando-se o estudo multicaso, o qual permite maior abrangência dos resultados, cruzando conclusões analíticas oriundas de dados obtidos nos sujeitos envolvidos.

O caráter exploratório e descritivo desta pesquisa é definido inicialmente, através de um estudo bibliográfico, para compreensão e delineamento de conceitos abordados na ciência geográfica e do fenômeno do turismo, assim como, um estudo documental o qual retrata aspectos histórico-culturais, econômicos (ciclos) e sócio-ambientais de cada município, direcionando também para a caracterização e conformação de cada área legalmente protegida.

Para coleta de dados, utilizou-se como método a aplicação de questionário aos conselheiros do Conselho Municipal de Meio Ambiente (COMDEMA) e Conselho Municipal do Turismo (COMTUR), a fim de obter informações de representantes de entidades e órgãos representativos na população joinvilense, principalmente no que se refere as deliberações do meio ambiente e do turismo.

Com relação a observação participante, abordada no início deste relatório, busca-se aplicar o método como proposta de interação, não somente com a comunidade de entorno, visitantes locais, turistas ou funcionários das áreas naturais protegidas, mas também com os gestores destas áreas.

Foram levantadas as principais questões relacionadas aos impactos ambientais, numa abordagem histórica, de diagnósticos e prognósticos, com o intuito de verificar o estágio atual das referidas áreas naturais protegidas. Identificaram-se também os segmentos de turismo já desenvolvidos nas áreas naturais protegidas e as ações para ordenamento territorial turístico e uso público das áreas naturais protegidas.

A partir das informações geradas com o levantamento bibliográfico e documental e da análise dos resultados das 25 entrevistas no COMDEMA dos 27 conselheiros existentes e 13 no COMTUR dos 15 conselheiros existentes, buscou-se sistematizar um esquema metodológico para identificação das potencialidades e dificuldades para o desenvolvimento do turismo, assim como formas de planejamento ambiental, ordenamento territorial e de fluxo turístico para as áreas naturais protegidas, a fim de contribuir para uma melhor gestão dos recursos naturais e culturais provenientes destes locais. 


\section{A gestão das áreas naturais protegidas e seu uso para o turismo em Joinville}

Destaca-se inicialmente que a área do município de Joinville tem $1.126,106 \mathrm{~km}^{2}$ apresentando aproximadamente $40 \%$ de área rural e natural. No censo demográfico de 2010, apresentado pelo IBGE (2015), Joinville apresentou 515.288 habitantes. Isto permite identificar uma demanda potencial por espaços de lazer. Dos 100.000 visitantes/ano da cidade, $26,20 \%$ dos turistas visitam as áreas naturais (SANTUR, 2012).

Com relação às áreas naturais protegidas, em sua quantidade, Joinville apesar de possuir oito ANP, sendo estas diferenciadas de acordo as categorias estabelecidas pelo SNUC, correspondem a 36\% do território de Joinville, totalizando em uma área de 41.419 ha.

\section{Caracterização do Órgão de Meio Ambiente}

Com o intuito de proteger o meio ambiente do município, Joinville apresenta uma Fundação Municipal do Meio Ambiente - FUNDEMA, criada no ano de 1990. Esta realiza diversas ações ligadas ao meio ambiente, podendo destacar o Monitoramento e Controle da Poluição Atmosférica, Programa de Certificação Ambiental, SOS Nascentes e o Plano Municipal de Gerenciamento Costeiro, Sistema de Gestão dos Recursos Hídricos e a Gestão das Unidades de Conservação.

Apesar da FUNDEMA não apresentar um plano estratégico, segue diretrizes e ações discutidas e propostas no Conselho Municipal do Meio Ambiente - COMDEMA, o qual aprova o relatório financeiro do Fundo Municipal do Meio Ambiente, o recurso do Plano Plurianual (PPA) do Município e das arrecadações durante os anos para ações e projetos da FUNDEMA.

Quanto à legislação ambiental, além da utilização do SNUC e do Sistema Estadual de Unidades de Conservação o município possui um Código Municipal do Meio Ambiente, instituído através da Lei Complementar no. 29, de 14/6/1996, um Código de Posturas, determinado pela Lei Complementar $n^{\circ}$. 84, de 12/1/2000 e a Lei ํ․ 5.712/2006 que dispõe sobre a Política Municipal do Meio Ambiente e sobre o Sistema Municipal de Meio Ambiente - SISMMAM.

Seguindo a legislação do município, instituída pela Lei no .2 .419 , de 27 de julho de 1990, cria-se a Fundação Municipal do Meio Ambiente FUNDEMA. Atribuída como fundação pública, vinculada a Prefeitura Municipal de Joinville, com o papel de articular, assegurar, elaborar, orientar, fiscalizar e assessorar atividades as quais condizem com a proteção do meio ambiente.

A estrutura organizacional básica exigida na Lei № . 2.419/90, determina que esta deverá compor um conselho deliberativo, uma diretoria e um conselho fiscal. Através de um estatuto, determinado pelo decreto $n \div$. 6.457/90 cria-se áreas técnicas com o intuito de deliberar funções práticas na gestão do meio ambiente no município. Atualmente, as atividades 
decorrentes das áreas técnicas, bem como outras atividades dentro da fundação, estão supervisionadas por quatro gerências e uma coordenadoria.

Destaca-se aqui a Gerência de Manutenção de Áreas Públicas (GEMAP) a qual é responsável em praticar a gestão relacionada à manutenção da arborização e vegetação de vias e logradouros públicos, através da coordenação e execução de ações de fiscalização e monitoramento, poda, corte e substituição de árvores, bem como roçadas; praticar a administração e fiscalização do serviço funerário, bem como desenvolver estudos, pesquisas, informações, projetos e ações ambientais voltados à preservação, conservação e recuperação; propor e desenvolver normatização ambiental das UC; promover a gestão ambiental das unidades de conservação e controlar, conservar e executar benfeitorias e reformas nas instalações dos cemitérios municipais.

A GEMAP, responsável pela gestão das UC, destina cerca de vinte e seis funcionários diretos para as atividades voltadas às UC do município. Dentre estes estão, o coordenador de UC, um funcionário para o Parque Municipal Morro do Finder (administração), dezenove funcionários no Parque Municipal Zôo-Botânico (administração, bióloga, veterinário, serviços gerais e tratadores), quatro funcionários no Parque Natural Municipal da Caieira, dois funcionários na Área de Proteção Ambiental Serra Dona Francisca (administração, técnico agrícola, fiscais) (LEPKA, 2012). Destaca-se que alguns destes funcionários, como é o caso do gerente, coordenador de UC, biólogos, serviços gerais e estagiários, destinam suas funções para as diferentes UC não se limitando apenas a uma área.

Acredita-se que apesar de apresentar uma legislação ambiental municipal, bem como seguir a legislação federal e estadual de UC, a Fundação Municipal do Meio Ambiente não atende as normas mínimas de conservação exigidas por estas, apresentando problemáticas quanto à gestão, bem como de infraestrutura de visitação.

\section{Caracterização do Conselho de Meio Ambiente}

Criado através do Decreto ํ. 5.807/1988 o Conselho Municipal do Meio Ambiente, órgão consultivo e de assessoramento do Executivo Municipal tem por objetivo a identificação de posturas que conduzam ao equilíbrio ecológico, considerando a utilização racional dos recursos naturais, permitindo o aproveitamento a fim de promover o bem estar social e desenvolvimento econômico.

Sua conformação inicial era composta por 13 membros representantes de entidades governamentais e entidades privadas, não havendo critérios de paridade. Eram 8 representantes de entidades governamentais (secretarias municipais, fundações municipais e estaduais, câmara de vereadores, etc.) e 5 de entidades privadas (instituições de ensino, associações, etc.).

A partir do Decreto ํo. 6.652/1991 o COMDEMA fica vinculado a Fundação Municipal do Meio Ambiente. Neste decreto estavam nomeados também 25 entidades, sendo 10 representantes de entidades governamentais e 15 de entidades privadas. Nota-se que neste momento já 
se têm maior participação de entidades privadas, principalmente de movimentos ecológicos, representados por 7 entidades.

No ano de 1993, altera-se novamente a conformação do COMDEMA, sendo que a partir do Decreto n‥ 7.122, mantém-se o número de entidades governamentais para 10 e diminui para 11 entidades privadas, destas apenas 2 entidades relacionadas a movimentos ecológicos. Neste decreto, acrescentou-se também a competência do presidente do Conselho, passando a ser o Diretor-Presidente da FUNDEMA o qual indicará também o secretário executivo. A partir deste decreto, caberá a FUNDEMA proporcionar a infraestrutura necessária para 0 funcionamento do COMDEMA.

Com o intuito de ampliação dos recursos para planos, programas e projetos visando a manutenção e melhoria da qualidade do meio ambiente de Joinville, aprova-se o Decreto № 8.298, de 30 de setembro de 1997, alterado pelo Decreto nㅇ 8.652/1998 e Decreto no 9.438/1999 que regulamenta o Fundo Municipal do Meio Ambiente - FMMA. O fundo passa a ser administrado pela FUNDEMA, porém submetido a demonstrações mensais de receita no COMDEMA. O FMMA também contempla financiamentos para projetos de educação ambiental, fiscalização, estudos e pesquisas, reflorestamentos em áreas de preservação permanente e unidades de conservação, monitoramento da qualidade ambiental, implantação e manutenção de unidades de conservação e recuperação de áreas degradadas.

Somente no ano de 2006 aprova-se o regimento interno do COMDEMA, através Decreto $\mathrm{n}^{\circ} 12.824$ e alterado pelo Decreto $\mathrm{n}$ ‥ 14.107/2008 onde se define a competência do Conselho e seus conselheiros. No regimento interno atribui-se aos conselheiros funções como o estudo e o relato de matérias que lhes forem submetidas, emitindo parecer; discutir e votar, apresentando emendas ou substitutivos às conclusões de pareceres; solicitar diligências ou vistas a processos; aprovar e assinar atas e reuniões plenárias, propondo ajustes necessários; requerer a convocação de reuniões plenárias extraordinárias justificando a sua necessidade; desempenhar os encargos que lhes forem atribuídos pela Presidente, ou propostos pelo próprio plenário; sugerir para apreciação, qualquer matéria a ser objeto de resolução e/ou proposição e participar de câmaras técnica, administrativa e especializadas.

As câmaras especializadas do COMDEMA surgem a partir da necessidade de análise de matérias complexas, cujo estudos prévios requeiram longo tempo, como estudos de impacto ambiental e aqueles relativas à Política Municipal de Meio Ambiente. Tem por finalidade também estudar, analisar e propor deliberações através de pareceres concernentes às matérias que previamente forem discutidas em reunião do conselho. Tais câmaras deverão ainda emitir pareceres de acordo as deliberações tomadas, estas serão respectivamente apresentadas ao plenário do Conselho.

Atualmente, estuda-se a possibilidade de criação de uma Câmara Especializada para a discussão e gestão das áreas naturais protegidas. Nesta câmara poderão estar inseridas as discussões de cada área, 
representadas respectivamente por entidades que compõem o conselho gestor. Porém serão necessárias alterações do regimento interno, ou talvez do decreto que institui o Conselho, para inserção e participação das entidades representativas dos conselhos gestores de cada área legalmente protegida.

No Decreto no 15.370/2009 nomeou-se como representantes do COMDEMA, 13 entidades governamentais e 14 entidades privadas. Cabe destacar que a partir deste último decreto surgem novas fundações municipais, como é o caso da Fundação Turística de Joinville e da Fundação Cultural de Joinville.

Também como ação e participação da FUNDEMA, destaca-se o Plano Municipal de Gerenciamento Costeiro como importante instrumento de gestão e planejamento da região costeira de Joinville, principalmente pelo alinhamento com o Plano Estadual de Gerenciamento Costeiro.

Acredita-se que a inserção das áreas naturais protegidas neste plano possibilitará a destinação e oficialização de políticas para a gestão, fiscalização e implementação de normativas que vêm de encontro com a proteção e conservação destes relevantes remanescentes florestais e histórico-culturais.

\section{Caracterização do Órgão de Turismo}

O órgão responsável pela divulgação e promoção dos atrativos turísticos naturais e de lazer é a Fundação Turística de Joinville PROMOTUR, criada a partir da Lei $n^{\circ} 4.676$ de 30 de outubro de 2002, entrando em atividade como fundação em 2003. Atribuída como fundação pública, vinculada a Prefeitura Municipal de Joinville, com o papel especial de executar a política municipal para o desenvolvimento do turismo, bem como: executar a política municipal para o desenvolvimento do turismo; divulgar as potencialidades turísticas do Município, incentivando os investimentos nesta área; incentivar o turismo industrial, comercial, cultural, rural, ecológico, tecnológico, científico e revigorar os eventos tradicionais da cidade; promover turisticamente as empresas do Município, mediante apoio logístico; incentivar e agilizar o intercâmbio com entidades congêneres, nacionais ou estrangeiras, públicas ou privadas, estabelecendo acordos, contratos ou convênios, com referendo da Administração Municipal; elaborar - calendário turístico anual do Município e supervisionar a sua operacionalização; e fortalecer o Conselho Municipal de Turismo.

A estruturação básica exigida pela Lei $n^{\circ} 4.676$ de 30 de outubro de 2002, determina que PROMOTUR esteja subordinada à proposição do Conselho Deliberativo, à aprovação do Poder Legislativo e à legislação pertinente. Sua estrutura compreende em um conselho deliberativo, diretoria e conselho fiscal.

$\mathrm{Na}$ organização da PROMOTUR, conforme o Decreto №. 12.716, de 13 de dezembro de 2005 que institui o estatuto, destaca-se a Gerência de Planejamento, a qual é responsável pela execução de diretrizes da PROMOTUR no que concerne a participação em programas de desenvolvimento turístico; representação da Fundação em eventos do 
turismo por outorga específica do diretor-presidente; emitir documentos básicos de administração compreendidos especialmente em sua esfera de atribuições; planejar, executar e acompanhar os projetos turísticos do poder público municipal; captar recursos para viabilização de ações de desenvolvimento turístico para a cidade; atuar, em parceria com entidades, na elaboração de diagnósticos, pesquisas e estudos do impacto do turismo no desenvolvimento local; supervisionar projetos e programas turísticos da PROMOTUR, como turismo rural, turismo histórico-cultural, turismo de eventos e negócios, pesquisa de demanda turística, banco de dados, entre outros de competência desta gerência, fornecendo suporte técnico e operacional.

Diante esta organização institucional a Fundação tem destinado esforços através da criação do Plano Estratégico da PROMOTUR 20092012 para o alinhamento com base em referenciais políticos e administrativos como os programas do Plano Nacional do Turismo - PNT, Plano de Desenvolvimento Integrado do Turismo Sustentável (PDITS), Programa de Desenvolvimento do Turismo do Sul do Brasil - PRODETURSUL e o Plano de Fortalecimento da Gestão Pública do Turismo de Joinville, aprovado pelo COMTUR no ano de 2009.

Para o cumprimento destas políticas de desenvolvimento do turismo, o Plano Estratégico da PROMOTUR 2009-2012 utiliza-se como temas principais a verticalização com os projetos federais, políticas de saúde, educação, planejamento urbano, desenvolvimento humano e inclusão social, garantia da sustentabilidade ambiental, valorização do planejamento estratégico do crescimento econômico, incentivo a economia solidária, política para os jovens, promoção a segurança alimentar, segurança com cidadania, valorização da inteligência local e a promoção de relações internacionais.

Tais temas surgem principalmente como sustentação para os principais projetos desta Fundação como o projeto de Legislação Municipal do Turismo que tem como ações a regularização do transporte turístico executivo, permitindo a operacionalização dos city-tours ${ }^{2}$ na cidade; a elaboração da Lei de criação do Fundo de Turismo, para incentivo ao desenvolvimento do turismo; criação do Plano de Desenvolvimento Rural para o alinhamento das políticas de desenvolvimento rural; viagens técnicas de integração intersetorial com secretarias e fundações parceiras, para estreitamento de relações e aprendizado; Plano de Marketing integrado com o trade Turístico; participação nos conselhos (Conselho da Cidade, Instância de Governança, Conselho do Meio Ambiente e Conselho da Cultura).

A Gerência de Planejamento responsável pela gestão de planejamento e apoio para captação de projetos turísticos para os segmentos de turismo em áreas naturais, turismo histórico-cultural, turismo de eventos e negócios e gestão e informação dos dados, destina como ações para as áreas naturais protegidas o acompanhamento através da coordenação de turismo em áreas naturais, que desenvolve um papel de articulação com a Fundação Municipal do Meio Ambiente - FUNDEMA para políticas de incentivo às áreas naturais protegidas inseridas no território de Joinvile e valorização dos atrativos e serviços do turismo presentes no interior e no entorno destas áreas; desenvolvimento do projeto de 
cicloturismo nas áreas naturais em parceria com a FUNDEMA, criação de material de divulgação como o mapa turístico rural e mapa urbano constando as unidades de conservação e principalmente os atrativos e serviços do turismo.

A Gerência de Planejamento consta ainda com 8 funcionários diretos e indiretos voltados para atividades relacionadas e inseridas nas as áreas naturais protegidas. Dentre estes estão a gerente, coordenador de turismo em áreas naturais e coordenador do turismo rural, coordenador do turismo histórico cultural, 3 atendentes turísticos para o portal de turismo rural e 1 administradora para o portal.

Observa-se uma organização e planejamento específico para a divulgação dos espaços da cidade, inclusive das áreas naturais protegidas. Este recente investimento na promoção de suas áreas naturais é identificado ainda como divulgação não massiva de forma profissional, focando exclusivamente para a APA da Serra Dona Francisca, especificamente nos segmentos do turismo rural e histórico-cultural os quais já estão consolidados no município e região, assim como na divulgação dos parques Zoo-botânico, Caieiras, Finder e Morro do Amaral, para o ecoturismo, turismo de aventura, focado na atividade de montanhismo, no turismo náutico o qual é realizado na Baía da Babitonga e também no turismo histórico-cultural, além de outros segmentos divididos nas demais localidades da cidade.

\section{Caracterização do Conselho de Turismo}

Criado através da Lei №. 3.169, de 21 de julho de 1995, o Conselho Municipal do Turismo - COMTUR surge com a finalidade de planejar, estabelecer e coordenar as ações voltadas à formulação da Política Municipal de Turismo de Joinville. O Conselho, dentre suas atividades, têm como objetivo definir a identidade turística do município; estimular investimentos públicos e privados visando estruturar a cidade com equipamentos turísticos; captar, sediar e promover eventos; divulgar 0 potencial turístico do município; conscientizar as lideranças públicas e privadas para importância do turismo no município e para promovê-lo de forma abrangente e mediante parcerias; elaborar e implantar o plano de "marketing" do turismo; elaborar o Plano Diretor do Turismo; sugerir alternativas para a reorganização da Secretaria Municipal de Turismo; e avaliar as ações desenvolvidas.

Dentre as 21 entidades que estavam representadas no Conselho, 9 compunham o grupo dos órgãos governamentais e 12 de entidades privadas (associações, sindicatos e universidade). A Lei no. 3.169/1995 instituía por decreto a nomeação dos conselheiros, que assumia um mandato de 2 anos. Esta Lei criou também os Comitês Político, Mercadológico, Operacional/Serviços e Infraestrutura dando subsídios para as deliberação assumidas pelo Conselho. Apesar do mesmo definir sua competência para elaboração de um regimento interno dentro de um prazo de 90 dias, somente a partir do Decreto №. 15.789/2009 que se aprova o Regimento Interno do Conselho Municipal do Turismo. 
No ano de 2006 altera-se a Lei n․ 3.169/1995 e sanciona a Lei no. 5.597 a qual acrescenta o conceito da Política Municipal de Turismo, que envolve as iniciativas ligadas ao turismo, originárias do setor privado ou público, assim como torna explícito o caráter permanente e deliberativo do COMTUR. Nesta Lei, o Conselho assume também funções normativas, consultivas, fiscalizadoras e de formação estratégica, atuando no acompanhamento, controle e avaliação do Fundo Municipal de Turismo FUMTUR, a ser criado por lei.

Com a criação do regimento interno (Decreto no. 15.789/2009), mantêm-se o caráter permanente e deliberativo do Conselho, assim como os objetivos do mesmo. Porém, definem-se as funções dos comitês, que passam a ser criados mediante as necessidades convocadas em assembléia geral pelos membros do Conselho. Os comitês passam a serem denominados como Comitê de Legislação e Certificação que identifica as políticas públicas existentes referentes às normatizações da atividade turística na cidade e propor alternativas para melhorias. O Comitê de Promoção, Comunicação e "Marketing" que propõem ações para o fortalecimento do destino Joinville. O Comitê de Capacitação e Qualificação que tem como função, identificar as necessidades de qualificação profissional da área turística e propõem estratégias de capacitação e, por fim, o Comitê de Planejamento e Gestão que define as estratégias de atuação do COMTUR.

Cria-se também no regimento interno as atribuições do presidente, vice-presidente, e secretário geral, assim como, os direitos e deveres dos conselheiros. Ainda em 2009, o COMTUR, representado por 15 conselheiros, 04 órgãos governamentais e 11 entidades da sociedade civil organizada, aprova o Planejamento Estratégico do Turismo de Joinville que têm como missão o fortalecimento do turismo de Joinville como atividade sustentável.

Busca-se com este planejamento sensibilizar a comunidade local e empresarial de Joinville da importância da atividade turística para o desenvolvimento sustentável do Município; discutir e analisar as políticas públicas do turismo em âmbito local e regional; incentivar a adequação da oferta turística de Joinville (meios de hospedagens, equipamentos de restauração, espaços de eventos, estrutura de entretenimento e de lazer); estabelecer normas, sanções e outras medidas que visem ordenar 0 desenvolvimento turístico em Joinville; estimular estratégias mercadológicas para a promoção e divulgação do turismo; e apoiar ações que viabiliza a capacitação e qualificação, da mão de obra gerencial e operacional de empreendimentos turísticos de Joinville.

Atualmente o COMTUR tem deliberado para a Fundação de Promoção e Planejamento Turístico de Joinville a criação do Fundo Municipal do Turismo - FUMTUR a fim de estimular a produção e execução de projetos turísticos considerados relevantes para o desenvolvimento da cidade. Bem como prover recursos para implantação de ações destinadas à gestão e promoção do turismo, de forma a garantir um desenvolvimento integrado e sustentável proporcionando elevação da qualidade de vida da população local e dos visitantes. 
Acredita-se que com a criação do FUMTUR poderá se destinar o financiamento direto para projetos que gerem desenvolvimento turístico sustentável, apresentados por pessoas físicas, jurídicas de direito público, jurídicas de direito privado sem fins lucrativos e de utilidade pública municipal.

\section{Caracterização das Áreas Naturais Protegidas}

Em destaque para as áreas naturais protegidas mais visitadas no município de Joinville, tem-se o Parque Municipal Zôo-Botânico, com aproximadamente 100.000 visitantes no ano de 2011. Outros destaques são o Parque Municipal Morro do Finder e o Parque Natural Municipal Caieira. O Parque Municipal Morro do Finder, que recebe constantemente visitantes, com fins educativos, científicos, recreativos e de lazer contemplativo. Em 2011, por exemplo, recebeu aproximadamente 7.200 visitantes, considerando ao mês uma média de 600 visitantes, sendo grande parte estudantes e escaladores. As visitas monitoradas são feitas mediante 0 agendamento na FUNDEMA. Outro destaque é o Parque Natural Municipal Caieira atingindo uma média de janeiro a dezembro de 2006, de aproximadamente 9.600 visitantes, considerando ao mês uma média de aproximadamente 800 visitantes, sendo uma pequena parcela deste total representado por um público de turistas, segundo relatos dos monitores do parque (LEPKA, 2012).

Destaca-se ainda, como unidade de conservação de grande relevância turística e principalmente ambiental, a APA da Serra Dona Francisca que apesar de ainda não apresentar um estudo de demanda para contabilizar o fluxo de visitantes em seu interior, destina uma estrutura de maior complexidade para a atividade de turismo, contando com diversos serviços turísticos (hospedagem, gastronomia, lazer, etc.), uma diversidade de atrativos naturais e culturais e principalmente a organização por parte da PROMOTUR para a divulgação das propriedades rurais que estão inseridas no segmento do turismo rural e que oferecem atividades de vivência rural, hospedagem rústica, gastronomia local e a comercialização de produtos coloniais.

As atividades de educação ambiental nas áreas naturais protegidas são realizadas principalmente no Parque Municipal Zoobotânico, Parque Natural Municipal da Caieira e Parque Municipal Morro do Finder. A FUNDEMA destina para estas áreas monitores ambientais que através de um agendamento realizam atividades de educação ambiental.

Diante tais dados citados reforça-se que o município dedicou até o momento esforços para a conservação das áreas naturais, estabelecendo, mesmo que superficiais, medidas para conservação das áreas naturais protegidas.

Buscando a realização de atividades de turismo em áreas naturais, o órgão municipal do turismo de Joinville (PROMOTUR) busca a organização e a definição de estratégias para o desenvolvimento do turismo e a consolidação de políticas públicas que possibilitem a regularização e 0 ordenamento da atividade de turismo sobre o território de Joinvile, 
respeitando o planejamento ambiental do município e dialogando entre as demais fundações relacionadas a fim de se consolidar um destino indutor capaz de atender diferentes públicos de turistas e principalmente possibilitar o desenvolvimento local das comunidades presentes.

Em um estudo de demanda turística, em Santa Catarina, especificamente no município de Joinville, segundo dados da Santur (2012), coletados no ano de 2008, cerca de $26,20 \%$ dos turistas que visitam a cidade, conhecem suas áreas naturais. A visitação nas áreas naturais protegidas de Joinville é feita principalmente pela população local, e uma pequena quantidade de turistas.

Buscando resumir esta caracterização, o Quadro 2 abaixo apresenta algumas informações relevantes:

Quadro 2: Análise da gestão das áreas protegidas de Joinville.

Table 2: Review of the management of protected areas of Joinville

\begin{tabular}{|c|c|}
\hline $\begin{array}{l}\text { Área do município e } \\
\text { parques }\end{array}$ & $1.131 \mathrm{~km}^{2}$ tendo $36 \%$ do território de parques \\
\hline $\begin{array}{l}\text { População (número de } \\
\text { habitantes) }\end{array}$ & 515.288 (IBGE, 2010) \\
\hline $\begin{array}{l}\text { Quantidade de áreas } \\
\text { legalmente protegidas }\end{array}$ & 08 \\
\hline Número de turistas & $\begin{array}{l}\text { Dos } 100.000 \text { visitantes/ano da cidade, 26,20\% dos turistas } \\
\text { visitam as áreas naturais (SANTUR, 2012) }\end{array}$ \\
\hline $\begin{array}{l}\text { Utilização das áreas } \\
\text { legalmente protegidas } \\
\text { para o turismo }\end{array}$ & $\begin{array}{l}\text { Branda } \\
\text { Recebe em sua maioria moradores e uma pequena } \\
\text { quantidade de turistas }\end{array}$ \\
\hline $\begin{array}{l}\text { Administração municipal de } \\
\text { turismo }\end{array}$ & $\begin{array}{l}\text { Fundação Turística de Joinville } \\
\text { Organização turística e promoção da cidade }\end{array}$ \\
\hline $\begin{array}{l}\text { Administração municipal de } \\
\text { meio ambiente }\end{array}$ & $\begin{array}{l}\text { Fundação Municipal de Meio Ambiente } \\
\text { Administra os parques }\end{array}$ \\
\hline $\begin{array}{l}\text { Legislações ambientais } \\
\text { municipais }\end{array}$ & Três específicas, utilizam-se as leis estaduais e federais \\
\hline $\begin{array}{l}\text { Adequação das UC na lei } \\
\text { federal brasileira }\end{array}$ & Apresenta relação direta, não cumprindo alguns pontos \\
\hline $\begin{array}{l}\text { Tipo de turismo } \\
\text { predominante realizado nas } \\
\text { áreas legalmente } \\
\text { protegidas }\end{array}$ & $\begin{array}{l}\text { Turismo de lazer } \\
\text { Turismo histórico-cultural } \\
\text { Turismo rural } \\
\text { Turismo de aventura }\end{array}$ \\
\hline Educação ambiental & Finder, Caieira e Zoobotânico \\
\hline Maior utilização geral & Conservação \\
\hline
\end{tabular}

Fonte: Autores. Source: Authors. 


\section{Análise estratégica da gestão pública municipal no desenvolvimento do turismo nas áreas naturais protegidas de Joinville}

Diante das estruturas de gestão do meio ambiente e do turismo, buscou-se através da aplicação de questionários quanti-qualitativos, caracterizar o perfil dos gestores do meio ambiente e do turismo de Joinville, bem como relatar opiniões com relação a gestão das áreas naturais protegidas e a possibilidade de desenvolvimento do turismo.

Para a consolidação dos resultados desta pesquisa, com base no diagnóstico realizado nas oito áreas naturais protegidas de Joinville e da análise das opiniões geradas a partir da aplicação de questionário para 38 conselheiros do COMDEMA e COMTUR, buscou-se através da análise DAFO, identificar as debilidades e fortalezas das áreas naturais protegidas e sua gestão, bem como, as ameaças que cercam estas áreas e as oportunidades para o desenvolvimento do turismo Quadro 3).

O cruzamento destas informações referentes às implicações encontradas no processo de implantação, gestão e atividades de visitação está sendo utilizada como instrumento para indicação de possibilidades e limitações da gestão para o desenvolvimento do turismo nas áreas naturais protegidas de Joinville.

Quadro 3: Análise DAFO realizada com os conselheiros do COMDEMA e COMTUR.

Table 3: SWOT analysis with the directors of COMDEMA and COMTUR .

\begin{tabular}{|c|c|}
\hline \multirow{22}{*}{ Pontos Fortes } & $\begin{array}{l}\text { Aplicação e o monitoramento de programas de recuperação de áreas degradadas (mata } \\
\text { ciliar) }\end{array}$ \\
\hline & $\begin{array}{l}\text { Desenvolvimento de um sistema de gestão cadastral para a área rural e planejamento } \\
\text { participativo para os planos de manejo }\end{array}$ \\
\hline & $\begin{array}{l}\text { Desenvolvimento de um Plano Municipal de Gerenciamento Costeiro que envolve o } \\
\text { zoneamento ecológico econômico de todo o território municipal }\end{array}$ \\
\hline & Recursos providos do FMMA para investimento na fiscalização e programas ambientais \\
\hline & Melhorias de infraestrutura (ARIE do Morro do Boa Vista) \\
\hline & Apoio a projetos direcionados ao estímulo de segmentos de turismo sustentável \\
\hline & $\begin{array}{l}\text { Proximidade com o centro urbano (ampla oferta de serviços turísticos como hospedagem } \\
\text { e alimentação) }\end{array}$ \\
\hline & Suficiente sistema de saúde e educação \\
\hline & Oferta gastronômica diversificada \\
\hline & Conservação dos recursos naturais (fauna, flora e recursos hídricos) \\
\hline & Presença de espécies endêmicas \\
\hline & Desenvolvimento de atividades de aventura (mountain bike e montanhismo) \\
\hline & Desenvolvimento de práticas de educação ambiental mediante agendamento \\
\hline & Planejamento de diferentes segmentos do turismo \\
\hline & Aumento da visitação nos últimos anos \\
\hline & $\begin{array}{l}\text { Criação de planos de manejo para algumas áreas (ARIE do Morro do Boa Vista e APA da } \\
\text { Serra da Dona Francisca) }\end{array}$ \\
\hline & $\begin{array}{l}\text { Planejamento para criação de novos planos de manejo (Parque Municipal Morro do } \\
\text { Finder e Parque Natural Municipal Caieira) }\end{array}$ \\
\hline & Preservação do patrimônio cultural \\
\hline & $\begin{array}{l}\text { Categorias de UC as quais permitem a permanência de comunidades tradicionais em seu } \\
\text { interior }\end{array}$ \\
\hline & $\begin{array}{l}\text { Presença de comunidades tradicionais no interior das áreas naturais protegidas atrativos } \\
\text { turísticos já consolidados no interior das áreas naturais protegidas. }\end{array}$ \\
\hline & Vias de acesso pavimentadas e devidamente sinalizadas \\
\hline & $\begin{array}{l}\text { Boa qualidade e preços favoráveis dos produtos oferecidos pelas comunidades } \\
\text { tradicionais. }\end{array}$ \\
\hline
\end{tabular}

Continua... 
...continuação.

\begin{tabular}{|c|c|}
\hline \multirow{27}{*}{ Pontos Fracos } & $\begin{array}{l}\text { Processo de gestão realizado pelo órgão municipal do meio ambiente de forma incipiente } \\
\text { e deficiente }\end{array}$ \\
\hline & $\begin{array}{l}\text { Falta de um corpo técnico para administração de cada área, ou seja, quadro funcional } \\
\text { insuficiente para manutenção da biodiversidade e a preservação de monumentos naturais }\end{array}$ \\
\hline & $\begin{array}{l}\text { Falta de infraestrutura para um receptivo e práticas de educação ambiental na maioria } \\
\text { das áreas naturais protegidas }\end{array}$ \\
\hline & Falta de recurso para manutenção das áreas \\
\hline & Falta de fiscalização \\
\hline & Divulgação inexpressiva \\
\hline & Falta de profissionalização do atendimento aos visitantes e turistas \\
\hline & Dificuldade de sinal de telefone em algumas UC \\
\hline & Segurança ineficiente (aumento de casos de assalto com moradores locais) \\
\hline & Baixa oferta de hospedagem e alimentação em alguma das regiões \\
\hline & Inexperiência e o desinteresse das agências de turismo receptivo para estas áreas \\
\hline & Falta de guias especializados para condução em áreas naturais \\
\hline & Inexistência de um controle de fluxo de visitantes \\
\hline & $\begin{array}{l}\text { Despejo do lixo doméstico e de construção civil em alguns locais das áreas naturais } \\
\text { protegidas }\end{array}$ \\
\hline & Corte indiscriminado de árvores nativas (roubo do palmito) \\
\hline & Presença de espécies invasoras \\
\hline & Caça e pesca predatória \\
\hline & Invasão através de trilhas secundárias \\
\hline & Depredação do patrimônio público (placas de sinalização e roubo de lixeiras) \\
\hline & $\begin{array}{l}\text { Intensiva visitação da comunidade joinvilense em períodos de verão nas margens dos } \\
\text { rios que abastecem a cidade }\end{array}$ \\
\hline & Inadequação de algumas unidades de conservação de acordo o SNUC \\
\hline & Falta de planos de manejo, \\
\hline & Situação de moradias irregulares e ocupação desordenada, \\
\hline & Queimadas em áreas de reflorestamento, \\
\hline & Extração mineral desordenada, \\
\hline & Falta de manutenção de trilhas \\
\hline & Desinteresse dos coordenadores para a gestão das áreas \\
\hline \multirow{19}{*}{ Oportunidades } & Apoio ao extrativismo e ao manejo ambiental \\
\hline & Pagamento por serviços ambientais \\
\hline & Incentivo as pesquisas científicas \\
\hline & $\begin{array}{l}\text { Avanço das tecnologias para o geoprocessamento (planejamento da área) e o } \\
\text { monitoramento ambiental }\end{array}$ \\
\hline & Capacitação e desenvolvimento das comunidades locais e conselhos gestores \\
\hline & Desenvolvimento de pesquisas e monitoramento de resultados \\
\hline & Organização de entidades representativas \\
\hline & Órgãos de meio ambiente e turismo com equipe técnica qualificada \\
\hline & Cidade com alto pode aquisitivo diante sua conformação industrial \\
\hline & Diversidade e valorização de grupos étnicos tradicionais (emigrantes europeus) \\
\hline & Ecossistemas preservados \\
\hline & Centro tecnológico bastante avançado \\
\hline & Leis e normas ambientais e de urbanismo bastante restritivas \\
\hline & Crescimento do associativismo como forma de gestão \\
\hline & $\begin{array}{l}\text { Joinville como cidade indutora da região norte do estado de Santa Catarina para o } \\
\text { turismo }\end{array}$ \\
\hline & Proximidade de grandes centros urbanos \\
\hline & $\begin{array}{l}\text { Fortalecimento e integração dos municípios para o desenvolvimento de roteiros } \\
\text { integrados para o turismo }\end{array}$ \\
\hline & Desenvolvimento da economia no município e o incremento dos investimentos no turismo \\
\hline & $\begin{array}{l}\text { Possibilidades de roteiros turísticos temáticos envolvendo as áreas naturais protegidas e } \\
\text { seus atrativos e o aumento da busca por produtos turísticos direcionados às áreas } \\
\text { naturais. }\end{array}$ \\
\hline
\end{tabular}

Continua... 
...continuação.

\begin{tabular}{|c|c|}
\hline \multirow{27}{*}{ Ameaças } & Presença das populações humanas \\
\hline & Expansão urbana e industrial desordenada \\
\hline & Desconhecimento das leis e normas por parte da população local \\
\hline & Baixa aplicação das leis, \\
\hline & Escassa educação ambiental no entorno \\
\hline & Dificuldade de contratação e manutenção de funcionários \\
\hline & Dificuldade de monitoramento de atividades ilegais \\
\hline & Facilidade de acesso favorecendo atividades ilegais (caça e pesca predatória), \\
\hline & Pressão imobiliária \\
\hline & Aumento da marginalidade \\
\hline & Desarticulação entre entidades privadas e do setor público \\
\hline & Atritos partidários e a descontinuidade de planos políticos \\
\hline & Mudanças locais e nacionais com relação ao sistema econômico \\
\hline & $\begin{array}{l}\text { Poluição atmosférica e dos recursos hídricos (despejo de esgoto e defensivos agrícolas } \\
\text { nos rios) }\end{array}$ \\
\hline & Desmatamento \\
\hline & Incêndios de origens antrópicas \\
\hline & $\begin{array}{l}\text { Contaminação genética de espécies exóticas e atividades agrícolas convencionais de } \\
\text { maior escala }\end{array}$ \\
\hline & Desastres naturais que possam comprometer a atratividade local \\
\hline & Turismo massificado/mal conduzido (tanto pelo trade turístico como pelo órgão público) \\
\hline & Descaracterização da paisagem natural e rural \\
\hline & Exclusão da comunidade local para a inserção de grandes empreendimentos turísticos \\
\hline & Competitividade entre mercados do mesmo segmento \\
\hline & Iniciativas isoladas para o desenvolvimento do turismo \\
\hline & Alto fluxo de migração para o município \\
\hline & Falta de infraestrutura adequada para um alto fluxo turístico \\
\hline & Sazonalidade da demanda \\
\hline & Falta de espaços alternativos de lazer para a comunidade de Joinville. \\
\hline
\end{tabular}

Fonte: Autores. Source: Authors.

De modo em geral, os conselheiros do COMTUR estão distantes do processo de gestão das áreas naturais protegidas, más reconhecem sua importância ambiental e para o turismo, tornando-os mais exigentes do ponto de vista da necessidade de uma gestão mais efetiva, assim como da melhoria das condições de infraestrutura para fiscalização e visitação. Porém, percebeu-se que os conselheiros do COMDEMA possuem maior clareza quanto às problemáticas ambientais. Considera-se ainda que por estes conselheiros perceberem melhor as problemáticas que os conselheiros do COMTUR, poderão contribuir mais na definição de ações para gestão ambiental das áreas, bem como, os conselheiros do COMTUR poderão contribuir mais quanto às soluções associadas às atividades de turismo sustentável nestas áreas.

Destaca-se ainda como desafio inserir constantemente na pauta dos conselhos a discussão das áreas naturais protegidas, mesmo que de forma incipiente. Seja em atividades que estejam relacionadas ao turismo, no COMTUR, ou então as problemáticas ambientais e soluções sustentáveis, considerando casos de sucesso que remetem às áreas naturais protegidas de Joinville, no COMDEMA.

Quanto às problemáticas identificadas nas áreas naturais protegidas, considera-se que tais devam ser sanadas ou ao menos discutidas tanto nas secretarias e fundações afins como nos conselhos que representam a sociedade, exigindo também o comprometimento das entidades no processo de educação (sensibilização) e fiscalização. Tendo em vista que problemas 
principalmente com a infraestrutura básica e regularização das áreas tem afetado diretamente as atividades do turismo, seja nas propriedades rurais da APA da Serra Dona Francisca, que atuam no segmento de turismo rural e necessitam de sistemas de gestão ambiental; seja nos serviços de alimentação oferecidos pela comunidade do Parque do Morro do Amaral; ou nos serviços de transporte turísticos que atuam nos city-tours; ou até mesmo quanto aos guias e condutores locais que necessitam de boas condições de trabalho ou na infraestrutura e segurança dos atrativos. Quanto maior a constatação por parte das agências e operadoras de turismo de problemáticas nas áreas naturais protegidas, menor será o grau de atratividade destas, e consequentemente, menor o fluxo de turistas, menor renda para a população local e menor será o recurso dos órgãos públicos e privados para a gestão destas áreas.

Em relação aos pontos fortes, indicadores apontam que a partir do planejamento participativo, que já vem sendo realizado em duas UC, se fortalece o compromisso da população com a gestão destas áreas. Ações como a aplicação e o monitoramento de programas de recuperação de áreas degradas, principalmente áreas de APP (mata ciliar, nascentes e encostas), o desenvolvimento de um sistema de gestão cadastral da área rural, 0 cruzamento do plano diretor e da lei de uso e ocupação do solo com o Plano Municipal de Gerenciamento Costeiro, possibilitam a ampliação das oportunidades, favorecendo os arranjos produtivos locais e 0 desenvolvimento do turismo.

Também como oportunidade para a consolidação de relevantes produtos turísticos direcionados para as áreas naturais, se pode identificar a abertura de concessões para operadoras de turismo nestas áreas, considerando o estado atual das áreas naturais protegidas de Joinville e no Brasil, principalmente sobre a falta de recurso para manutenção, fiscalização e infraestrutura, como mostra o relatório do IBAMA e WWF-Brasil (2007). Esta prática já é aplicada em diversas Unidades de Conservação no país, e segundo Rocktaeschel (2010), a concessão de determinados serviços direcionadas para o uso turístico das áreas naturais protegidas apresenta como possibilidade de sustentabilidade financeira. No entanto, destaca-se a necessidade de aproximação do órgão gestor do meio ambiente com o órgão gestor do turismo. A utilização dos respectivos conselhos (guardachuva) para tais discussões possibilitará reunir os demais conselhos gestores que consequentemente deverão ter autonomia de gestão.

Conforme Rothert et. al. (2004) os investimentos na promoção das áreas naturais de Joinville, especificamente nos segmentos do turismo rural e histórico-cultural, iniciaram no final de 1992, ainda pela Secretaria de Turismo. O projeto piloto de turismo rural, iniciado na localidade do Rio Bonito - Estrada Bonita tinha como parceria a Fundação Municipal 25 de Julho $^{3}$ e os proprietários rurais. A estrutura inicial deste projeto piloto contemplava uma divulgação massiva, atingindo principalmente a mídia local, estadual e nacional. Fato que gerou inúmeras discussões e estimulou a aproximação dos diferentes atores envolvidos (órgãos governamentais, entidades privadas e população local) para resolução dos problemas e planejamento das futuras ações. 
O processo de planejamento e articulação pôde ser considerado intenso conforme identificado nos relatórios dos técnicos da PROMOTUR e nas atas apresentadas durante os encontros da Associação Eco-Rural, e de acordo com os relatos dos professores das instituições de ensino que participaram do processo de articulação e planejamento do turismo rural e que atualmente se encontram como conselheiros no COMTUR. Além dos relatos e documentos, constataram-se também inúmeras problemáticas que até o momento são identificadas pelos atores envolvidos (principalmente com os proprietários rurais e empreendedores que se localizam no espaço rural) como uma etapa não superada.

Com relação ao planejamento e promoção das áreas naturais, especificamente as áreas naturais protegidas no município, identificou-se como prioridade da PROMOTUR o desenvolvimento de um material de divulgação que dê o apoio básico para segmentos específicos como o de turismo rural, já consolidado e inserido na APA da Serra Dona Francisca, com o intuito de atingir um público específico, além do que já frequenta, para então minimizar o impacto gerado por um fluxo massivo de turistas em propriedades, atrativos e equipamentos turísticos. Acredita-se também que com a elaboração de um plano de manejo para a unidade de conservação, ferramentas como o cálculo da capacidade de suporte, e programas como educação ambiental e melhoria da infraestrutura, poderão ser implementadas também nas propriedades, atrativos e equipamentos turísticos.

Apesar das áreas naturais protegidas apresentarem uma relevante quantidade de atrativos turísticos (naturais e culturais), estes ainda não possuem infraestrutura suficiente, instrumentos para controle e pesquisa de demanda de visitantes, assim como controle de fluxo de visitantes, conforme defendido por Hardt (2007). Tambem se identifica a falta de ordenamento territorial e um material consistente para divulgação das áreas naturais protegidas, inclusive em outras línguas como inglês e espanhol. Nota-se que os atendentes turísticos possuem pouca informação científica sobre as áreas naturais protegidas.

De acordo Irving (1999), Oliveira e Oliveira (1999) práticas de educação ambiental através da aplicabilidade de metodologias lúdicas de indivíduos e grupos comunitários têm-se demonstrado como importantes alternativas para a transformação dos problemas em soluções.

Além do turismo rural, o ecoturismo, o turismo de aventura e o turismo cultural também são segmentos desenvolvidos no interior e no entorno da APA da Serra Dona Francisca, porém ainda podem-se considerar atividades não tão significativas do ponto de vista de fluxo turístico. O ecoturismo, assim como, o turismo de aventura, são operados por apenas uma empresa que oferece pacotes para atividades de trekking aliadas a prática de educação ambiental e contemplação da natureza nas montanhas do município e região. A empresa conta também com condutores especializados para o acompanhamento de atividades de montanhismo (escalada e travessias). O segmento de turismo cultural, apesar de apresentar um pequeno fluxo de turistas, está inserido também nos pacotes oferecidos pelas agências de receptivo, que se mistura com as vivências do turismo rural e do agroturismo. 
Esta proposta de promoção abrange também a área urbana do município, a qual concentra áreas como Parque Zoobotânico, Caieiras, Finder e Reserva da llha do Morro do Amaral, que diante suas características naturais e culturais, possibilitam 0 desenvolvimento dos segmentos de ecoturismo e turismo de aventura, focado na atividade de montanhismo, no turismo náutico o qual é realizado na Baía da Babitonga e também no turismo histórico-cultural, além de outros segmentos divididos nas demais localidades da cidade.

\section{Considerações finais}

Pode-se dizer que Joinville se destaca pelo número e extensão de áreas naturais protegidas, porém apresenta um incipiente processo de implementação da gestão efetiva de áreas publicas, comprometendo os objetivos fundamentais de conservação e preservação, assim como as atividades de visitação e o desenvolvimento de diferentes segmentos do turismo.

Este processo de análise possibilitou não somente a caracterização destes espaços e a compreensão da gestão pública, mas a identificação dos principais problemas e limitações existentes nas áreas naturais protegidas e em seus respectivos órgãos gestores bem como das principais potencialidades de soluções.

A aplicação do estudo multicaso, através de métodos exploratórios e de observação, tem demonstrado um caminho eficiente, possibilitando a análise entre as dificuldades de gestão das áreas naturais protegidas do município e as potencialidades para o desenvolvimento do turismo.

A caracterização das áreas naturais protegidas possibilitou identificar e expressar a diversidade natural de cada área, assim como a multiculturalidade das comunidades locais e de entorno. A identificação do fluxo de visitantes nas áreas naturais protegidas também pôde ser considerada como relevante do ponto de vista da representatividade turística e de lazer (Finder, Caieira e Zoobotânico) para a FUNDEMA e PROMOTUR. Identificou-se a necessidade de um acompanhamento por parte da PROMOTUR no que se refere à pesquisa de demanda turística nestas áreas que sofrem um processo de visitação, porém, sem nenhum instrumento profissional e técnico do turismo que identifique o fluxo de visitantes, assim como facilite o processo de "captação" destas informações como o uso de equipamentos e profissionais capacitados no turismo.

A constatação da falta de conhecimento de grande parte dos conselheiros com relação às áreas naturais protegidas de Joinville demonstra a importância e a necessidade de desenvolvimento de um programa de sensibilização e conscientização dos conselheiros neste sentido.

Destaca-se também a necessidade de construção de ferramentas informativas (cartilhas temáticas, sites interativos, vídeos, etc) a serem elaboradas pelos órgãos gestores do meio ambiente e do turismo com o intuito de informar tanto a população joinvilense como os turistas que buscam visitar estas áreas, considerando que a maioria dos conselheiros 
entrevistados não teve acesso a informações das áreas naturais protegidas do município.

Percebe-se a importância da discussão da gestão dos municípios por meio do planejamento efetivo, que beneficie a população e gere oportunidades de desenvolvimento. Neste contexto as áreas naturais protegidas são espaços que podem contribuir nestas questões, pois conservam o patrimônio natural, e podem proporcionar o lazer e servem de atrativo para o turismo, podendo produzir impactos socioeconômicos positivos (GÂNDARA; ALBACH; VIEIRA, 2013).

As áreas naturais contribuem para a imagem turística do município, no entanto, necessita-se ainda fortalecer ações estratégicas (como as consultas públicas referentes aos planos de manejo, entre outras ações pontuais) relacionadas ao planejamento participativo e gestão através de instrumentos participativos como o plano de gerenciamento costeiro que deverá possibilitar uma gestão integrada das áreas naturais protegidas. Com a estruturação destas áreas e de suas possíveis atividades é que se fará possível a divulgação e promoção das atividades de turismo das áreas naturais protegidas.

O desenvolvimento gerado através dos serviços de comércio, gastronomia, hospedagem, agricultura, entre outras atividades que agregadas ao turismo, cumprindo as normas dos planos de manejo, possibilitará maiores subsídios para a sustentabilidade das áreas naturais protegidas de Joinville.

A gestão do ponto de vista do turismo deve aproveitar o fator de diversidade e valorização dos grupos étnicos locais, assim como sua posição de cidade indutora da região norte do Estado, para integrar os municípios vizinhos e potencializar os roteiros de turismo. Estes roteiros podem ser temáticos a fim de atingir públicos específicos, como é o caso do segmento do ecoturismo e do turismo de aventura, ambos podendo ser desenvolvidos em áreas naturais protegidas.

A rediscussão e organização dos conselhos municipais, especificamente do os do meio ambiente e do turismo, que teoricamente assumem o compromisso e se relacionam diretamente ou indiretamente com estas áreas, assim como, o planejamento e execução dos órgãos públicos competentes inseridos também como representantes da gestão pública municipal, deverão fundamentar as tomadas de decisões sobre 0 desenvolvimento do turismo em áreas naturais protegidas de Joinville, assegurando a adequada conservação dos recursos naturais que proporciona uma boa qualidade de vida para os moradores locais e do entorno e tornam destas áreas um atrativo turístico, estimulando para 0 desenvolvimento de novas práticas sustentáveis para o turismo. 


\section{Referências bibliográficas}

BARRETTO, M. Planejamento responsável do turismo. Campinas-SP: Papirus, 2005.

CARLOS, A.F.A. O turismo e a produção do não-lugar. In: YÁZIGI, E.; CARLOS, A. F. A.; CRUZ, R. C. A. (orgs.). Turismo: Espaço, paisagem e cultura. São Paulo: Editora Hucitec, 1996.

CASTRO, I.E. et al. (Orgs). Geografia: conceitos e temas. Rio de Janeiro: Bertrand Brasil, 2003.

CRUZ, R.C.A. Geografia do turismo: de lugares a pseudo-lugares. São Paulo: Roca, 2007.

CLAVAL, P. Geografia cultural: o estado da arte. In: ROSENDAHL, Z.; CORRÊA, R. L. Manifestações da cultura no espaço. Rio de Janeiro: EDUERJ, 1999.

CORIOLANO, L.N.M.T. O turismo e a relação sociedade-natureza: realidades, conflitos e resistências. Fortaleza: EdUECE, 2007.

CORIOLANO, L.N.M.T. (Org.). Arranjos produtivos locais do turismo comunitário: atores e cenários em mudanças. Fortaleza: EdUECE, 2009.

GANDARA, J. ; ALBACH, V. Turismo en áreas naturales en destinos urbanos en el sur de Brasil: gestión de áreas protegidas. In: GONZÁLEZ HERNÁNDEZ, M.M.; LEÓN GONZÁLEZ, C.J.; DE LEÓN LEDESMA, J.; MORENO GIL, S. (Eds.). Turismo rural $\mathbf{y}$ en areas protegidas. 1ed.Madrid: Sintesis, 2013.

HAESBAERT, R. Identidades territoriais. In: ROSENDAHL, Z.; CORRÊA, R.L. Manifestações da cultura no espaço. Rio de Janeiro: EDUERJ, 1999.

HAESBAERT, R. Território e multiterritorialidade: um debate. Revista GEOgraphia. Ano IX, n. 17, 2007.

HARDT, L.P.A. Planejamento de unidades de conservação. In: Curso de Planejamento e Manejo de Áreas Naturais Protegidas, 2007, Guaraqueçaba. Apostila... Guaraqueçaba: Fundação $O$ Boticário de Proteção à Natureza, 2007.

IBAMA. Instituto Brasileiro do Meio Ambiente e Recursos Naturais Renováveis. Efetividade de gestão das unidades de conservação federais do Brasil: implementação do método Rappam. IBAMA, WWFBrasil. Brasília: IBAMA, 2007

IBGE. Instituto Brasileiro de Geografia e Estatística. Censo Demográfico e Geociências. Disponível em: <http://www.ibge.gov.br>. Acesso em 15 abr 2015.

IRVING, M. Participação e envolvimento comunitário: garantia ética de sustentabilidade em projetos de desenvolvimento. Revista Espaço e Geografia, Rio de Janeiro, Ano II, n²1, 1999.

LEFEBVRE, H. A Revolução Urbana. Tradução de Sergio Martins. Belo Horizonte. Ed. UFMG. 1999. 
LEFEBVRE, H. O direito à cidade. tradução Rubens Eduardo Frias. São Paulo: Centauro, 2000.

LEPKA, D. Parques. [mensagem pessoal]. Mensagem recebida por <daniel@fundema.sc.gov.br> em 11/06/2012.

MINISTÉRIO DO TURISMO. Projeto inventário da oferta turística: manual do pesquisados formulários. Brasília: MTUR, 2006.

OLIVEIRA, R.; OLIVEIRA, M. Pesquisa social e ação educativa: conhecer a realidade para poder transformá-la. In: BRANDÃO, C. (Org.) Pesquisa participante. São Paulo: Brasiliense, 1999.

ROCKTAESCHEL, B. M. M. M. Marco conceitual e diretrizes para terceirizações administrativas em unidades de conservação. Artigo disponível:

$<$ http://www.ibama.gov.br/siucweb/guiadechefe/guia/anexos/anexo7/index.ht m>. Acessado em: 05/2010.

RODRIGUES, A.B. (org.). Turismo e geografia: reflexões teóricas e enfoques regionais. São Paulo: Hucitec, 1996.

RODRIGUES, A.B. Turismo e espaço: rumo a um conhecimento transdiciplinar. 2ª ed. São Paulo: Hucitec, 1999.

ROTHERT, D.C. et al. Portal turístico rural de Joinville - Casa Krüger: a gestão pública integrada para o desenvolvimento do turismo rural na cidade. In: Anais do IV Congresso Internacional Sobre Turismo Rural e Desenvolvimento Sustentável. Joinville: BOM JESUS/IELUSC, 2004.

SANTUR. Santa Catarina Turismo S/A. Dados do Turismo em Santa Catarina. Joinville: SANTUR, 2012.

VALLS, J-F. Gestão integral de destinos turísticos sustentáveis; trad. Cristiano Vasques e Liana Wang. Rio de de Janeiro: Editora FGV, 2006.

XAVIER, H. A percepção geográfica do turismo. São Paulo: Aleph, 2007.

YIN, R.K. Estudo de caso: planejamento e métodos. 3. ed. Porto Alegre: Bookman, 2005.

\section{Notas:}

${ }^{1}$ Esta discussão foi realizada por ALBACH, V. M. e VIEIRA, V. B.

Macroambiente em diagnósticos de destinos turísticos: reflexões e suportes para análises em pesquisa bibliográfica e documental no V Seminário da Associação Nacional de Pesquisa e Pós-Graduação em Turismo - V ANPTUR. 2008.

2 Passeio pelos pontos turísticos da cidade (HOLLANDA, 2003).

${ }^{3}$ Órgão municipal destinado para a assistência técnica rural 
Vinicius Boneli Vieira: Universidade Federal do Paraná, Curitiba, PR, Brasil.

E-mail: viniciusbonelli@gmail.com

Link para o currículo Lattes: http://lattes.cnpq.br/0246902049266303

José Manoel Gonçalves Gândara: Universidade Federal do Paraná, Curitiba, PR, Brasil.

E-mail: jmggandara@yahoo.com.br

Link para o currículo Lattes: http://lattes.cnpq.br/2820622668034670

Data de submissão: 25 de novembro de 2012

Data de recebimento de correções: 18 de fevereiro de 2015

Data do aceite: 18 de fevereiro de 2015

Avaliado anonimamente 